\title{
La teoría de la apariencia en Marx y sus raíces kantianas ${ }^{1}$
}

\section{Marx' Theory of Appearance and its Kantian Roots}

\author{
Clara Ramas San Miguel ${ }^{2}$ \\ Universidad de Zaragoza (España)
}

Recibido: 09-11-18

Aprobado: 02-07-19

\section{Resumen}

En este artículo se presenta una interpretación de la crítica de la economía política de Marx como teoría filosófica: una teoría de la apariencia que tiene sus raíces en la intervención kantiana en la historia de la metafísica. En primer lugar, se presenta el proyecto de la crítica de la economía política como una crítica de la "apariencia real" "objetiva" [realer, gegenständlicher Schein]. A continuación, se apunta a "fetichismo" y "mistificación" como las categorías centrales de esta teoría de la apariencia marxiana. Después se precisa su origen y posibilidad en el espacio filosófico abierto por Kant y Hegel, que sientan las bases de una teoría de la apariencia propiamente moderna. Finalmente, se profundiza en esta relación

\footnotetext{
${ }^{1}$ Este trabajo ha sido realizado en el marco de los siguientes Proyectos de Investigación: "Naturaleza y comunidad IV: El filósofo, la ciudad y el conflicto de las facultades, o la filosofía en la crisis de la humanidad europea del Siglo XXI" (Ref. FFI2017-83155-P), financiado por Ministerio de Economía, Industria y Competitividad; "POSTORY: Historiadores, Mnemohistoria y artesanos del pasado en la era posturístic"a (AGREEMENT NUMBER: 2013 - 1572 / 001 - 001 CU7 MULT7), financiado por CE. EACEA. Culture. Multianual Cooperation Projects. 2007-2013; y "Precariedad, exclusión y diversidad funcional (discapacidad): lógicas y efectos subjetivos del sufrimiento social contemporáneo (II). Innovación docente en Filosofía" (Ref.: Innova-Docencia, Proyecto No 84), financiado por la Universidad Complutense de Madrid.

${ }^{2}$ (clara.ramas@pdi.ucm.es) Doctora Europea de Filosofía por la Universidad Complutense de Madrid y profesora Ayudante Doctor en la Universidad de Zaragoza, actualmente en excedencia por cargo público. Su investigación se centra en la filosofía política y la ontología social contemporáneas. Entre sus últimas publicaciones cabe destacar "La idea de Europa de Hugo von Hofmannsthal (1914-1927) en el contexto de la Revolución Conservadora", Anales del Seminario de Historia de la Filosofia, 36-2, 2019, pp. 461-476, y Fetiche y mistificación capitalistas. La crítica de la economía politica de Marx, con un prólogo de Carlos Fernández Liria y un epílogo de Michael Heinrich, Siglo XXI, Tres Cantos, 2018.

ORCID: https://orcid.org/0000-0003-3598-3556.
} 
entre Marx y Kant mostrando que es posible clarificar tanto las diferencias como los contenidos del fetichismo y la mistificación al hilo de las dos clases de apariencia pensadas por Kant -según la distinción de Lebrun-, "apariencia lógica" y "apariencia trascendental".

Palabras-clave: Crítica de la economía política, apariencia, fetichismo, mistificación, apariencia lógica, apariencia trascendental.

\begin{abstract}
This paper provides an interpretation of Marx' critique of political economy as a philosophical theory: a theory of appearance rooted in Kant's intervention in the history of metaphysics. First, the project of a critique of political economy is portrayed as a critique of the "real", "objective appearance" [realer, gegenständlicher Schein]. Secondly, "fetichism" and "mystification" are designated as the central categories in Marx' theory of appearance. Then its origin and possibility are located in the philosophical space opened by Kand and Hegel with their specifically modern theory of appearance. Lastly, the bond between Marx and Kant is further investigated by showing that both the contents and the differences of fetichism and mystification can be clarified with regard to the two types of appearance or illusion that, according to Lebrun, Kant distinguishes: "logical" and "transcendental illusion".
\end{abstract}

Key-words: Critique of Political Economy, Appearance, Fetichism, Mystification, Logical Illusion, Transcendental Illusion.

No busquéis nada tras los fenómenos; los fenómenos mismos son la teoría.

Goethe

\title{
¿Marx, filósofo? La crítica de la economía política como crítica de la apariencia
}

En 2017 se publicaban las actas del Congreso internacional "Dialéctica Materialista: Lecturas de Marx en diálogo", que tuvo lugar en 2015 en la Freie Universität de Berlín. Frieder Otto Wolf, en su Prólogo a este libro, afirmaba:

El corte científico realizado por Marx -no directamente, como aún creía Althusser, para investigar el "Continente Historia", sino para la comprensión científica del dominio del modo de producción capitalista en la sociedad moderna burguesa, en el cual todavía vivimos- no ha conducido inmediata, 
automáticamente a la formación de una "filosofía marxista" que correspondiera a este corte ${ }^{3}$.

Las tres tradiciones que habrían tratado de abrir este camino, según Wolf, serían la del hegelo-marxismo, la Teoría Crítica de la Escuela de Frankfurt y la escuela althusseriana. Seguir pensando esa filosofía, las aportaciones de estos debates y qué puede descartarse o llevarse más lejos, considera el profesor alemán, es tarea hoy de todos los intelectuales que se consideren herederos del trabajo de Marx.

Muchos autores, sin embargo, han considerado que Marx es solamente un economista que se limita a proseguir el descubrimiento de Ricardo del secreto oculto del plusvalor: la explotación de la fuerza de trabajo ${ }^{4}$. Una vez abandonada la ruidosa esfera del intercambio, presente a la luz del día, para descender a "los oscuros talleres de la producción" y desvelar el secreto oculto del capital, como relata teatralmente Marx a las puertas de la sección tercera, la tarea habría quedado completada. Pero no se explicaría, entonces, que Marx dedique otros dos libros enteros a desarrollar categorías, incluyendo rúbricas tan literario-filosóficas hacia el final del libro III como "La Fórmula Trinitaria" o "La apariencia [Schein] de la competencia".

Lo planteó perfectamente Heinrich en el apartado de su Wissenschaft vom Wert titulado, precisamente, "La teoría del capital como destrucción de la apariencia [Schein] de la empiria capitalista". Essabido que el objetivo del análisis de Marx era desenmascarar el secreto del plusvalor, descubrir la cualidad oculta del valor de poner valor, porque es valor. En estas formulaciones, dice Heinrich, se expresa que la empiria capitalista no es transparente, sino que debe ser descifrada, como no puede ser de otro modo, con ayuda de categorías no empíricas. Marx hace esto, en principio, con su teoría del plusvalor, el análisis de las relaciones entre trabajo y capital en el proceso inmediato de producción, que desvela el secreto del plusvalor. Pero con esto "[...] aún no está aclarado por qué tiene que haber en general un secreto, por qué la empiria capitalista se presenta de esta manera y no de otra". Marx “[...] no sólo descifra las relaciones que subyacen a esta empiria, sino que muestra la superficie empírica como expresión necesaria de aquellas relaciones, $[\ldots]^{\prime \prime 5}$.

\footnotetext{
${ }^{3}$ Stefano Breda, Kaveh Boveiri, Frieder Otto Wolf (eds.), Materialistische Dialektik bei Marx und über Marx hinaus, Berlin, Freie Universität Berlin 2017, p. 5.

4 Es por ejemplo el caso de Joseph Alois Schumpeter, "Karl Marx (1818-1883). La doctrina marxista" [en Diez grandes economistas: de Marx a Keynes, Madrid, Alianza Editorial, 1997], pp. 33 y ss.

Michael Heinrich, Die Wissenschaft vom Wert, Münster, Westfälisches Dampfboot, 2011, p. 306. Hemos desarrollado con más detalle la temática de Marx como filósofo de la apariencia y sus relaciones con Kant y Hegel en Clara Ramas San Miguel, Hacia una teoría de la apariencia. Fetichismo y mistificación en la crítica de la economía politica de Marx [tesis doctoral], Madrid, UCM, 2015< https://eprints.ucm.es/34214/1/T36659.pdf $>$.
} 
Žižek también ha subrayado que Marx está fuera el esquema dualista metafísico tradicional de una esencia oculta frente a una apariencia falsa: el análisis de Marx es un "análisis de forma". Por ello, afirma, "El 'secreto' a desvelar mediante el análisis no es el contenido que oculta la forma [...], sino, en cambio, el 'secreto' de esta forma. [...]. El problema real no es penetrar hasta el 'núcleo oculto' de la mercancía -la determinación del valor que tiene por cantidad de trabajo consumido en la producción de la misma- sino explicar por qué el trabajo asumió la forma del valor de una mercancía, [...]"․ No se trata para Marx de encontrar una esencia oculta y verdadera, el secreto del plusvalor, frente al mero fenómeno, sino de hacer el camino opuesto: elaborar por qué los contenidos sólo pueden manifestarse con esas formas, o, dicho de otro modo, cuáles son las condiciones de aparición de lo que aparece.

Entonces, ¿acaso ha terminado Marx cuando descubre el fundamento oculto de las formas visibles, básicamente, la explotación y la producción de plusvalor? ¿Por qué entonces dedicar su esfuerzo a exponer la necesidad de que de aquellas relaciones emerjan estas formas? Lo dice muy claro en Teorías del plusvalor:

En esta forma completamente alienada de la ganancia, y en el mismo grado en que la figura de la ganancia esconde su núcleo interno, el capital recibe más y más una figura cósica, se convierte, de relación, cada vez más en una cosa; pero una cosa que tiene en su cuerpo a la relación social, que se la ha tragado, una cosa que se comporta hacia sí misma con vida ficticia y autonomía, un ser sensible-suprasensible. Y en esa forma de capital y ganancia, él aparece como presupuesto terminado en la superficie. Es la forma de su realidad o, mejor dicho, su forma de existencia efectiva [Es ist die Form seiner Wirklichkeit oder vielmehr seine wirkliche Existenzform $]^{7}$.

Este texto es clave. La forma de aparición del capital como ganancia, donde el capital se aleja y se enajena cada vez más de su naturaleza interna, adquiriendo una forma completamente irracional y contradictoria, es la única forma en la que él existe. No cabe diferenciar entre, por un lado, la existencia pura e incontaminada del capital como esencia y, por otro, su degeneración en una forma ilusoria. Esta forma, por ajena, mistificada e inverosímil que parezca, es la forma en que se da, y como tal, el objeto obligado del análisis: "Tomar tales expresiones [imaginarias] por meras licentia poetica muestra sólo la

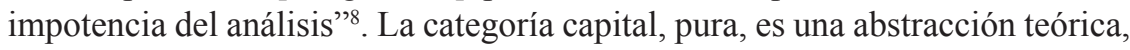

\footnotetext{
${ }^{6}$ Slavoj Žižek, S., El sublime objeto de la ideología, México, Siglo XXI, 1992, pp. 35-36.

7 Karl Marx, Theorien der Mehrwert, Marx-Engels Werke, Berlin, hrsg. Vom Institut für Marxismus-Leninismus beim Zk der SED, 1956 ff., Bd. 26.3, p. 474. Traducción nuestra. Las obras de Marx se citan según esta edición, como MEW seguidas del número de tomo y página.

${ }^{8}$ Karl Marx, Das Kapital. Kritik der politischen Ökonomie. Erster Band: Der Produktionsprozess des Kapitals, Marx-Engels Werke, Berlin, hrsg. Vom Institut für Marxismus-Leninismus beim Zk der SED, 1956 ff., Bd. 23, p. 559, nota 26. Se refiere aquí Marx a Proudhon, que señalaba que "valor del 
que nos permite descifrar las formas realmente existentes como resultado y que nos muestra que éstas, aunque parecen presupuestos ya dados, son en realidad formas mediadas. Pero estas formas fenoménicas en la superficie son la realidad efectiva, la única forma de existencia de las categorías abstractas. Y todo se juega, en el análisis, en demostrar cómo el ser-capital llega a manifestarse de aquellas maneras. Es decir, cómo las relaciones esenciales, que gobiernan el todo estructurado que es la sociedad capitalista, se manifiestan en su superficie, siendo, a la vez, lo primero -lo más inmediato-y lo último -lo más mediado-. ${ }^{9}$ De nuevo en palabras de Heinrich:

Este "mundo encantado" del que habla Marx no es ninguna superficie inesencial de las relaciones esenciales, es la única forma de la realidad de estas relaciones, y con ello asimismo el fundamento para la percepción de la sociedad burguesa, de la conciencia que resulta de ella y de las acciones construidas sobre ella. El fetichismo no es una "falsa conciencia", se adhiere a las propias relaciones de producción burguesas. Los hombres perciben las relaciones de producción capitalistas tal y como aparecen, sólo que estas relaciones aparecen de otro modo a como son. La conciencia cotidiana, tanto del trabajador como del capitalista, está atrapada en un mundo de apariencia [in einer Welt des Scheins $]^{10}$.

La expresión "mundo de la apariencia" es literal de Marx ${ }^{11}$. En el libro III encontramos expresiones como "la apariencia probada por la forma autónoma, invertida de las partes del valor, [...]"12. " [...]el movimiento efectivo aparece, necesariamente, en una figura invertida: [...]. Esta apariencia habría de nacer necesariamente, pues [...]"13. Y, hacia el final, recapitula de este modo: "Todas las formas sociales, en la medida en que conducen a la producción de mercancías y a la circulación del dinero, toman parte en esta inversión [Verkehrung]. Pero en el modo de producción capitalista y en el capital, que constituye su categoría dominante, su relación de producción determinante, este mundo encantado e

trabajo" es una "expresión figurada", a lo cual responde Marx que, viendo en la fructífera realidad de la mercancía "trabajo" sólo una "elipsis gramatical", Proudhon convertía la entera sociedad existente, que reposa en el carácter de mercancía del trabajo, en una licencia poética, con lo cual cabría pensar que bastaría con dirigirse a la Academia de la lengua para "evitar todos los sufrimientos que padece nuestra sociedad". Estas formas irracionales son, para Marx, la realidad misma: no cabe soslayar este hecho de ningún modo.

9 El esquema que opera aquí es el del concepto de "relación esencial" [wesentliches Verhältnis] y "fenómeno" [Erscheinung] de La ciencia de la lógica de Hegel. Sobre el papel de la Lógica de Hegel en Marx, cf. Dieter Wolf, "Warum konnte Hegels Logik Marx große Dienste leisten?" [en C.E. Vollgraf, R. Sperl, R. Hecker, R., (eds.), Beiträge zur Marx-Engels-Forschung, Neue Folge 2010, Hamburg, Argument, 2010].

${ }^{10}$ Heinrich, M., Die Wissenschaft vom Wert, op. cit., p. 309

11 Marx, K., Das Kapital. Kritik der politischen Ökonomie. Dritter Band: Der Gesamtprozess der kapitalistischen Produktion, Marx-Engels Werke, Berlin, hrsg. Vom Institut für MarxismusLeninismus beim Zk der SED, 1956 ff., Bd. 25, p. 838.

${ }^{12}$ MEW 25, p. 876.

13 MEW 25, p. 877.

Araucaria. Revista Iberoamericana de Filosofia, Política, Humanidades y Relaciones Internacionales, año $22, \mathrm{n}^{\circ} 43$. Primer semestre de 2020. Pp. 169-195. ISSN 1575-6823 e-ISSN 2340-2199 https://dx.doi.org/10.12795/araucaria.2020.i43.08 
invertido se desarrolla mucho más allá" ${ }^{14}$. La crítica de la economía política, pues, tiene por objeto un mundo invertido, un mundo de formas de apariencia que son formas de existencia de relaciones efectivas: un mundo invertido. Es evidente que se requiere del lenguaje de la tradición filosófica para comprender qué está en juego en todo ello.

\section{Fetichismo y mistificación como formas de apariencia}

Fetichismo y mistificación son las categorías centrales de la teoría de la apariencia de Marx. Con estas categorías Marx designa las "formas absurdas" bajo las que aparece el modo de producción capitalista y que, a su vez, quedan fijadas como "las categorías de la economía burguesa". Éstas son categoría irracionales, pero a la vez "socialmente válidas, esto es, formas de pensamiento objetivas para las relaciones de producción [...]"15, en la medida en que no constituyen desvaríos sin fundamento o errores cualesquiera de conocimiento, sino que recogen el carácter cosificado, invertido, tergiversado de la existencia real de esas relaciones de producción. Esta imagen invertida [verkehrt] emerge por sí sola, necesariamente, de esas relaciones. Lo que aparece, entonces, no deja ver inmediatamente las condiciones de su aparición, y la economía política, como forma de conocimiento, no hace sino permanecer atrapada en lo que inmediatamente aparece, reproduciéndolo espontáneamente, sin preguntar por la razón o la condición de su aparición:

No nos puede maravillar, por ende, que precisamente en la forma enajenada de aparición de las relaciones económicas, donde éstas son prima facie contradicciones absurdas y consumadas [...], que precisamente aquí, decíamos, la economía vulgar se sienta perfectamente a sus anchas y que esas relaciones se le aparezcan como tanto más evidentes cuanto más escondida está en ellas la conexión interna, pero más correspondan a la representación ordinaria ${ }^{16}$.

Así pues, el economista burgués, "cuyo limitado cerebro no es capaz de separar la forma de aparición de aquello que en ella aparece, $[\ldots]^{117}$, es un esclavo de la apariencia. La economía política reproduce sin reflexión una estructura de lo real atravesada por la inversión y con un cierto juego complejo entre las relaciones económicas y sus formas de aparición. Frente a semejante formación

${ }^{14}$ MEW 25, p. 835.

${ }^{15}$ MEW 23, p. 90. Un excelente análisis de esta problemática en Hans-Georg Backhaus, "Zur Marxschen «Revolutionierung» und «Kritik» der Ökonomie: die Bestimmung ihres Gegenständes als Ganzes «verrückter Formen»", en: Dialektik der Wertform. Untersuchungen zur Marxschen Ökonomiekritik, Ça Ira, Freiburg, 2011, pp. 299-333.

${ }^{16}$ MEW 25, p. 825.

17 MEW 23, p. 594. 
de saber su crítica es "ciencia", porque ofrece un conocimiento efectivo de las relaciones que articulan la sociedad moderna del que la economía política no ha sido capaz. Pero este conocimiento como ciencia, dice Marx, sería superfluo "si la forma de aparición y la esencia de las cosas coincidiesen inmediatamente"18. precisamente porque parte de asumir que no coinciden, la crítica pregunta por las condiciones de aparición de lo que aparece. Marx plantea, pues, un cierto juego de relación y distancia entre la forma de manifestación o aparición [Erscheinungsform] y lo que ahí constituye esencia o realidad; y persigue en lo que inmediatamente aparece una cierta dimensión de apariencia [Schein], su necesidad y sus efectos específicos en esa constitución real. La crítica de la economía política contiene, por consiguiente, una teoría de la apariencia, pero de una apariencia "socialmente necesaria" u "objetiva" [gegenständlich], esencial al movimiento de la sociedad moderna.

La crítica de la economía política de Marx es, por tanto, la deconstrucción del modelo de realidad efectiva subyacente a esas problematizaciones y categorías: un análisis de la inversión incrustada en la realidad misma que determina un desfase constitutivo entre la forma de manifestación y las relaciones efectivas, de modo que un complejo juego de formas de apariencia y aparición se hace valer como parte constituyente de lo real. Lo que se juega en la crítica de la economía política es, además de la crítica categorial de una ciencia, en una palabra, un nuevo planteamiento de la cuestión filosófica a secas, en el que las formas de conciencia, y las estructuras de apariencia que se administran en ellas, se imponen como eje ineludible de la indagación y determinación moderna de en qué consiste ser.

El significado de estas categorías de fetichismo y mistificación ha sido tradicionalmente soslayado en la recepción de la obra de Marx. Se ha obviado, en primer lugar, cómo las formas de fetichismo y mistificación articulan internamente el texto de Marx. Nos hemos ocupado en otros lugares de esta recepción y elaborado una propuesta de interpretación de la crítica de la economía política a partir de estos conceptos ${ }^{19}$. En esta ocasión, sin embargo, se trata de explorar el significado filosófico de esas categorías, de ese esqueleto organizador, para intentar descubrir en él los fundamentos de una "teoría de la apariencia". Categorizados por el propio Marx como "formas de apariencia" [Erscheinungsformen], los fenómenos estructurales estudiados en ella bajo las denominaciones de "fetichismo" y "mistificación" constituyen, en efecto, un momento esencial de una interpretación de la sociedad moderna, y de un diagnóstico de lo real, que subvierte el reparto metafísico tradicional de las relaciones de ser y aparecer, y dota de una paradójica efectividad a

\footnotetext{
18 MEW 25, p. 825.

${ }^{19}$ Clara Ramas San Miguel, Fetiche y mistificación capitalistas. La crítica de la economía política de Marx (con un prólogo de C. Fernández Liria y un epílogo de Michael Heinrich), Tres Cantos, Siglo XXI, 2018.
}

Araucaria. Revista Iberoamericana de Filosofia, Política, Humanidades y Relaciones Internacionales, año $22, \mathrm{n}^{\circ} 43$. Primer semestre de 2020. Pp. 169-195. ISSN 1575-6823 e-ISSN 2340-2199 https://dx.doi.org/10.12795/araucaria.2020.i43.08 
lo fantasmático como lo más propio la condición contemporánea de nuestra existencia histórica. Esta teoría se sitúa en inmediato diálogo con la tradición filosófica, pues teoría de la apariencia ha hecho siempre la historia de la filosofía: la tensión de que haya algo entre el ser y el puro no-ser ha agitado al pensar desde sus comienzos con Parménides y los pre-socráticos. La teoría de la apariencia de Marx es, pues, relevante para una discusión con esta tradición filosófica y metafísica, especialmente en sus representantes modernos de Kant y Hegel. Sólo en diálogo con ella puede comprenderse plenamente estos conceptos y hacer justicia a toda su carga filosófica.

¿En qué consisten? Ambas formas recorren diversas categorías económicas y cuentan con una como su forma matriz que se replican en formas ulteriores ${ }^{20}$. En el caso del fetichismo, la mercancía es la forma base. La definición de fetichismo de la mercancía en El capital es la siguiente:

Lo misterioso de la forma mercancía consiste pues, simplemente, en que ella devuelve a los seres humanos el carácter social de su propio trabajo reflejado como carácter objetivo de precisamente los productos de trabajo, como propiedades naturales-sociales de estas cosas; y por ello también devuelve la relación social de los productores con el trabajo total reflejada como una relación social de objetos que existiera fuera de ellos. Mediante este quidproquo los productos de trabajo se transforman en mercancías, cosas sensiblemente suprasensibles o sociales. [...] Se trata tan sólo de la determinada relación social de los seres humanos, que toma aquí para ellos la forma fantasmagórica de una relación entre cosas"21.

Se trata pues de un proceso doble. La forma mercancía refleja algo como algo para los seres humanos, a saber, "el carácter social de su propio trabajo" como una propiedad de las cosas; y la mercancía refleja otro algo, "la relación social" como otro algo para ellos, a saber, como una relación social que existiera autónomamente. Es decir, por un lado, a estas personas les parece que esas cosas poseen como propiedades naturales lo que en rigor no son sino sus propias relaciones ${ }^{22}$. Puede denominarse a esto, Marx lo hace en otros textos, "personificación de las cosas". Por otro lado, la relación entre las personas parece reducirse o consistir en una relación entre cosas. A las personas en relación se les aparece su propia relación como si fuera una relación no

${ }^{20}$ Las hemos recorrido en Clara Ramas San Miguel, C., Fetiche y mistificación capitalistas, op. cit., caps. III y IV, pp. 69-150.

21 MEW 23, pp. 86-87.

22 Como señala Marx en el análisis del equivalente de la forma valor, solemos entender que las propiedades de una cosa no nacen de su relación con otras cosas, sino que más bien sólo se ponen en ejercicio en esta relación. Por ello, por mucho que la propiedad de representar trabajo inscrita en la mercancía la reciba únicamente a partir de ser puesta en relación con otras mercancías y, por ende, de referir unos trabajos a otros, inevitablemente surge la apariencia de que esta mercancía posee por sí sola la propiedad de representar trabajo como una capacidad suya. 
entre ellos, sino entre las cosas. Es decir, "cosificación de las personas"23. Esta forma de cosificación recorre también las categorías de dinero y de capital ${ }^{24}$. Fetichismo ocurre, pues, allí donde una relación social aparece cosificada como propiedad de un objeto.

El salario es la forma matriz de la mistificación. Marx se refiere así al salario como precio del trabajo: "Esta forma de manifestación, que hace invisible la relación efectiva y muestra justamente su contrario, $[\ldots]$. ${ }^{25}$. Y: "En la expresión 'valor del trabajo', el concepto de valor no solo se ha disuelto completamente, sino que se ha invertido y transformado en su contrario" 26 . Se ve que Marx utiliza el término "mistificación" para designar una forma de manifestación que oculta la realidad efectiva y muestra "lo contrario" de ésta; o bien, recíprocamente, para designar una realidad que se manifiesta como invertida. No hay, por un lado, una realidad efectiva, y, por otro, una forma de manifestación falsa o aparente. Es la propia relación efectiva-valor- la que se ha invertido y transformado en su contrario: ella se muestra en esa forma de manifestación, solo que de otro modo. Es una y la misma realidad la que se manifiesta como invertida o contraria a lo que es, o, dicho de otro modo, esta forma de manifestación no es sino la propia realidad en cuestión apareciendo de cierto modo peculiar, a saber, invertido. La mistificación rodea, también, a las formas de la renta de la tierra, el interés y la ganancia. En suma, "mistificación" ocurre cuando una relación social aparece necesariamente como invertida.

Entonces, para poder plantear la pregunta a la que se refería Wolf arriba, la pregunta por la "filosofía" que habría de acompañar o que sostiene "la comprensión científica del dominio del modo de producción capitalista en la sociedad moderna burguesa", o, dicho de otro modo, para pensar la filosofía que acompaña o sostiene el proyecto de la Crítica de la economía política de Marx, es necesario preguntar cuáles son las categorías de la misma que conectan especialmente con la tradición filosófica y contienen una específica carga filosófica. Sin embargo, lamentablemente, éstas son categorías tradicionalmente ignoradas en la recepción marxista. Sólo existe, que conozcamos, una obra monográfica sobre la cuestión de la apariencia en Marx: Der reale Schein und die Theorie des Kapitals bei Marx, de A. M. Fischer; y, como no podía ser de otro modo, otorga un lugar especial al fetichismo y la mistificación. Esta obra, bastante desconocida, es esencial en primer lugar porque no se limita, como es el caso en la enorme mayoría de estudios, a la figura del fetichismo de la mercancía, sino que recoge como la categoría de apariencia recorre todas las categorías que estructuran la crítica de la economía política, desde el principio al final.

\footnotetext{
${ }^{23}$ Para un estudio de la dimensión de cosificación en el fetichismo, cf. Henrik Wallat, "Der Begriff der Verkehrung im Denken von Marx” en Marx-Engels Jahrbuch 2004 (2005), pp. 68-102.

${ }^{24}$ Ver por ejemplo MEGA II/6, p. 37 o MEW 25, p. 835.

25 MEW 23, p. 562.

${ }^{26}$ MEW 23, p. 559.
}

Araucaria. Revista Iberoamericana de Filosofia, Politica, Humanidades y Relaciones Internacionales, año $22, \mathrm{n}^{\circ} 43$. Primer semestre de 2020. Pp. 169-195. ISSN 1575-6823 e-ISSN 2340-2199 https://dx.doi.org/10.12795/araucaria.2020.i43.08 
El autor elabora el índice de la obra recogiendo a los aspectos de la realidad capitalista a los cuales "se adhiere la apariencia real": el fetichismo de la mercancía y la contradicción en la mercancía, la dialéctica de la forma valor, el proceso de intercambio, la circulación o el dinero, el capital como forma de aparición y finalmente, "El fetiche del capital desde el valor que engendra valor al capital que rinde interés. La figura de la superficie del modo de producción capitalista como un mundo encantado e invertido". Puede decirse que Fischer elabora así una tópica de la apariencia en Marx. A partir de aquí, Fischer va tejiendo el análisis de un tipo de apariencia [Schein] idiosincrásica porque es real, es decir, un componente ontológico de la realidad efectiva, no una mera ilusión, y va desgranando los lugares de lo real en que se manifiesta ${ }^{27}$.

Si uno quiere saber lo que significa "apariencia real" en Marx, dice, lo normal es que recurra al apartado 4 del capítulo 1 de El capital: el fetichismo de la mercancía. Esto es un error en varios sentidos, de los cuales nos interesa sobre todo uno: que al hacer esto se toma la teoría del fetichismo de la mercancía por una teoría completa de la apariencia. Esto no puede ser: el mundo encantado del fetiche y la mistificación se extiende mucho más allá. En el todo múltiple y complejo que es la sociedad burguesa, determinado por la categoría del capital, que atraviesa y constituye todas las demás relaciones, se da una inversión, un encantamiento, en suma, una apariencia, inaudita hasta entonces, incluso contando con las sociedades donde aparece circunstancialmente el tráfico de mercancías y de dinero. Esta sociedad, auto-comprendida por sí misma como la organización más racional, pragmática, eficiente e ilustrada existente hasta el momento a lo largo de la historia, se presenta aquí como un "mundo invertido y encantado". Fischer define la tarea que se perfila a partir de aquí: "Se trata de perseguir el desarrollo de la inversión y de la apariencia en las contradicciones del capital que se despliega hasta 'su forma más ajena y peculiar': el capital que rinde interés, al que Marx denominó una vez la madre de todas las formas absurdas" ${ }^{28}$. Se establece aquí así, con todo rigor, el propósito de desarrollar una "teoría de la inversión y de la apariencia" en Marx.

¿Cuáles serían los lugares de esta teoría de la apariencia? El fetichismo sería sólo un escalón en el despliegue de la apariencia real, pero quizás el fundamental. Aparece también al fetiche del dinero y del capital en el camino hacia la figura consumada de la apariencia. Ésta sería, como decía Marx, la figura acabada de la superficie del modo de producción capitalista. Esta superficie, la figura del capitalismo, tal como ella aparece y existe en realidad para sus participantes, es la que recoge y abarca en sí todas las figuras de la apariencia. Es ésta un mundo invertido y encantado, que no sólo esconde, en

${ }^{27}$ Anton M. Fischer, Der reale Schein und die Theorie des Kapitals bei Marx, Zürich, Europa Verlag, 1978, p. 47 y ss.

28 Anton M. Fischer, op. cit., p. 49.

Araucaria. Revista Iberoamericana de Filosofia, Politica, Humanidades y Relaciones Internacionales, año 22, $\mathrm{n}^{\circ} 43$. Primer semestre de 2020. Pp. 169-195. ISSN 1575-6823 e-ISSN 2340-2199 https://dx.doi.org/10.12795/araucaria.2020.i43.08 
expresión de Marx, "la figura de su núcleo interno, esencial, pero escondido, y el concepto que le corresponde" 29 , sino que lo niega y tergiversa. Esta superficie de apariencia, analizada y diseccionada, es el punto de llegada de la teoría. La tarea de la ciencia es para Marx, en lugar de quedar en la superficie de los fenómenos, como hacía la economía política vulgar, "[...] reducir el movimiento visible, que meramente aparece, al movimiento interno, efectivo" ${ }^{30}$. Se apunta así a "la estructura oculta del sistema económico burgués", que presenta "lo invisible y lo esencial que ha de ser investigado"31. Con esto, se gana de nuevo, se recobra el punto de partida: la superficie, el fenómeno, lo que aparece, pero ahora determinado de modo concreto. La crítica de la economía política de Marx, recapitula Fischer,

“[...] reconduce la estructura desplegada de la inversión, como se muestra en la
superficie de los fenómenos y 'donde la mediación no sólo se hace invisible, sino
que se expresa su contrario directo' (26.3, 504), a sus momentos más simples.
Se muestra aquí que el desarrollo de las categorías económicas corresponde a
correlativos niveles de la inversión o figuras de la apariencia" 32 .

Así, el método de Marx consiste en partir de la superficie de los fenómenos, analizarlos en su naturaleza, encontrando las mediaciones y las categorías rectoras y determinantes, y reconstruirlos mediante la "exposición dialéctica": "[...] el análisis es, empero, el presupuesto necesario de la exposición genética, del aprehender el proceso de configuración efectiva en sus diversas fases" ${ }^{\prime 33}$.

El lenguaje a veces casi dualista de Marx - esencia-fenómeno, visibleinvisible- no ha de confundir: el movimiento acaba allí donde empezó, en lo que aparece, en el fenómeno. Esto, no otra cosa, era lo que había que ganar en el análisis. No hay un trasmundo verdadero detrás. Acabamos donde empezamos, en el fenómeno, sólo que ahora la apariencia ha quedado puesta ante los ojos y comprendida en su mediación, comprendido el movimiento efectivo y real, que la incluye como parte integrante. No se trata, en modo alguno, de reducir la apariencia y desecharla como mera ilusión; se trata de hacer ver que el momento de apariencia es parte integral de lo que hay tal y como aparece, es decir, del fenómeno. Queda claro esto en la última frase de Fischer: en la crítica de la economía política, esta construcción teórica que reproduce dialécticamente, es decir, mediante un logos que atraviesa, el todo estructurado de la sociedad burguesa, todas las categorías parte del desarrollo corresponden con niveles, figuras o formas de apariencia. Por 1o tanto, estas formas de apariencia han de ser parte integrante de la exposición

\footnotetext{
${ }^{29}$ MEW 25, p. 219.

${ }^{30}$ MEW 25, p. 324.

${ }^{31}$ MEW 26.2, p. 162 y 25.

${ }^{32}$ Anton M. Fischer, op. cit., p. 50.

${ }_{33}$ MEW 26.3, p. 491.
} 
[Darstellung] del objeto, o dicho de otro modo: la crítica de la economía política es una teoría de la apariencia. El programa de Fischer, asumido aquí, consiste precisamente en esto: rastrear el despliegue de las formas de inversión o apariencia real [realer Schein] en las categorías económicas de Marx, que exponen y reproducen el todo estructurado del modo de producción capitalista, y mostrar así que la crítica de la economía política de Marx es, efectivamente, en tanto que estudio de esas formas, una teoría de la apariencia.

\section{La teoría moderna de la apariencia}

La presencia de la cuestión de la apariencia en la historia de la filosofía es una evidencia; ahora bien, dentro de esto, ¿cómo acotar el campo en que aparece Marx? Creemos que, en primer lugar, dentro de la tradición moderna; y, dentro de ésta, en continuidad con Kant y Hegel.

H. Heinz-Holz, en su introducción al trabajo de Fischer, desarrolla el contexto filosófico moderno para sostener la tesis de que hay que entender a Marx como un filósofo, y concretamente como continuador de la filosofía moderna de Kant y Hegel $^{34}$. Comienza realizando lo que bien podría ser la distinción filosófica por excelencia, la distinción entre ser y pensar: pensar sería aquel ser peculiar que, siendo él mismo, puede hacer el ser mismo objeto y contenido; es decir, puede abrir un espacio de manifestación para que las cosas se muestren tal y como son. Aquí se ve muy claramente que la pregunta por la apariencia acompaña desde el comienzo a la interrogación filosófica, que desde antiguo pregunta: ¿cuáles son las condiciones de manifestación de lo que hay?

Kant, como ha mostrado también Deleuze, constituye el fundador moderno de una teoría de la "apariencia objetiva" [gegenständlicher Schein] ${ }^{35}$. Que la apariencia es objetiva para Kant significa que no la considera un error o ilusión, sino necesaria, estructural, una dimensión constitutiva de lo real. En correspondencia con esto, Kant elabora un concepto de fenómeno que no se reduce a mera apariencia, sino que es la única realidad existente. Kant revoluciona así el presupuesto presente en la mayor parte de la anterior historia de la filosofía de que la apariencia tiene su sede en los sentidos o en la imaginación. Por una parte, subvertirá el dualismo razón - sentidos afirmando, en una anticipación de temas que luego desarrollará Nietzsche, que la razón tiene un "interés práctico" en lo incondicionado. Por otra parte, dotará a la apariencia de un estatuto ontológico que no tenía antes: como reconoce elogiosamente Hegel en la Ciencia de la Lógica, Kant inició el camino para comprender que las contradicciones y el infinito constituyen lo real, al convertir a la dialéctica en

\footnotetext{
${ }^{34}$ Anton M. Fischer, op. cit., 1978, pp. 7-11.

35 Gilles Deleuze, Kant y el tiempo Buenos Aires, Cactus, 2008, p. 25 y ss.
} 
una operación necesaria de la razón: reconocía así, justamente, "la objetividad de la apariencia"36.

Heinz-Holz señala que Hegel daría todavía un paso más allá de Kant al pensar la apariencia [Schein] como dotada de objetividad, y ello en un sentido no sólo trascendental o referido a una subjetividad ${ }^{37}$. En la Ciencia de la lógica, la apariencia es el "poner" propio de la esencia, y la esencia la mediación entre ser y concepto; la esencia es mediación y negatividad. La esencia no es para Hegel, como en su definición tradicional, un compendio de notas o realidades obtenido por abstracción, lo cual sería un mero producto de la reflexión extrínseca y abstracta; la esencia posee su propio movimiento, y éste es una negatividad propia por la cual se separa del ser y éste se vuelve, por así decirlo, hacia sí mismo y hacia el interior de sí mismo. Así presenta Hegel la primera entrada en escena de la apariencia:

La esencia proviene del ser: en esa medida, no es inmediatamente en y para sí, sino un resultado de aquel movimiento. O bien la esencia, tomada por lo pronto como algo inmediato, es entonces un determinado estar, al cual le está enfrentado otro; ella es sólo estar esencial frente a algo inesencial. La esencia es empero el ser asumido en y para sí; lo que a ella le está enfrentado es solamente apariencia. Sólo que la apariencia es el propio poner de la esencia ${ }^{38}$.

La apariencia es el poner de la esencia. Esa negatividad suya es la reflexión, mediante la cual la esencia refleja o establece sus propias determinaciones. La lógica de la esencia, así, y en la medida en que contiene la apariencia como resultado de la reflexión, puede concebirse, afirma HeinzHolz, como un tipo de lógica trascendental en sentido kantiano, es decir, fundante de objetividad. La reflexión en Hegel, en efecto, posee el estatus de "pensamiento", un ejercicio del cogito, pero no en un sentido subjetivo o idealista, del mismo modo que lo trascendental en Kant, a diferencia de lo trascendente, contiene de suyo una referencia al objeto -en forma de condición de posibilidad ${ }^{39}$ - La apariencia no es para Hegel una mera "cosa de pensamiento", sino el ser real de la negatividad de la esencia cuando se niega a sí misma como ser determinado. Con ello, dice Holz, por un lado, como reflexión, se conserva el carácter trascendental de la apariencia; pero, por otro, la apariencia es ahora estatus ontológico de una individualidad que se pone como determinada frente a lo universal, y con ello se reconoce

36 “[...] pero la idea general que él sitúa a la base y a la que ha dado por ello valor es el carácter objetivo de la apariencia y la necesidad de la contradicción, [...]" (Georg Wilhelm Friedrich Hegel, Ciencia de la lógica. Vol. I: Lógica objetiva (1812-1813), edición de F. Duque, Madrid, Abada, 2011, p. 205).

${ }^{37}$ Anton M. Fischer, op. cit., p. 8 y ss.

${ }^{38}$ Hegel, G. W. F., Ciencia de la lógica, op. cit., p. 441.

39 Para esta diferencia, cf. Juan Manuel Navarro Cordón, "El concepto de 'trascendental' en Kant", Anales del Seminario de Metafísica, vol. 5, no 5 (1970), pp. 55-78.

Araucaria. Revista Iberoamericana de Filosofia, Política, Humanidades y Relaciones Internacionales, año $22, \mathrm{n}^{\circ} 43$. Primer semestre de 2020. Pp. 169-195. ISSN 1575-6823 e-ISSN 2340-2199 https://dx.doi.org/10.12795/araucaria.2020.i43.08 
su objetividad. Así pues, primera nota de la comprensión hegeliana de la apariencia: la apariencia posee existencia, no es una quimera o ilusión. Es el ser mismo, en su nulidad respecto a la esencia: "el ser es apariencia", dice Hegel, pero entonces, la apariencia es ser. Lo afirma Hegel tal cual: "La segunda [proposición]: la esencia es ser, constituye el contenido de la sección primera de la doctrina de la esencia", esto es, de la doctrina de la reflexión, donde está contenida la apariencia: "Pero este ser en que la esencia se ha convertido es el ser esencial, la existencia; un ser que ha surgido de la negatividad e interioridad" 40 . La apariencia es, pues, ser y existencia.

Lenin recoge este aspecto en su comentario a la Lógica de Hegel, donde atribuye a "la objetividad de la apariencia" un particular valor. Así Lenin aquí, dice Heinz-Holz, no situaría la cuestión de la apariencia en el terreno de la ideología, sino que permanecería en terreno hegeliano al concebir la apariencia como un fenómeno del ser: apariencia sería la nulidad de lo individual, el ser-momento de lo que está dado. Sólo porque lo ente es, y por ello de suyo pertenece a la apariencia, sólo por eso puede tener lugar en la conciencia una inversión entre condición y condicionado que podemos denominar "ideología” o "falsa conciencia”. Esta estructura de inversión, sigue Heinz-Holz, es lo que Marx recoge como "fetichismo": y su caracterización como "apariencia objetiva" [gegenständlicher Schein] deja claro que no se trata aquí de una apariencia que nace del pensamiento, sea como error, mentira o ilusión, o cualesquiera de las modalidades previas del cogito, sino de una apariencia en la cosa misma.

Es llamativo, concluye Heinz-Holz, que los análisis de la estructura lógica de El capital se limiten a tematizar el juego entre esencia y fenómeno o aparición [Erscheinung], es decir, la contraposición perteneciente a la parte central de la Lógica de la esencia, pero ignoren el papel fundamental de la apariencia. Lo que desde luego es evidente es que puede hablarse de una teoría de la apariencia en sentido amplio en Marx. Marx recoge, en fin, la indicación de Kant vía Hegel sobre la "apariencia objetiva", asumiendo plenamente una ontología de lo que aparece y sus condiciones de aparición, no de la mera apariencia y la esencia oculta ${ }^{41}$. Marx recoge, con ello, una pregunta que inquieta a la filosofía desde Platón y Parménides: la pregunta por el estatuto de la apariencia. Con ello Marx entra de pleno derecho en el diálogo que constituye la historia de la metafísica, en especial desde el giro impreso a la misma por la categoría kantiana de "apariencia objetiva" y su desarrollo en Hegel.

40 Ibid., p. 535.

${ }^{41}$ El término "apariencia objetiva" aparece referido al valor en MEW 23, p. 88. 


\title{
Arqueología de una distinción: fetichismo y mistificación, apariencia dialéctica y apariencia lógica
}

Además de heredar el marco general kantiano de una teoría de la apariencia que reconoce la objetividad de una apariencia real, el tratamiento concreto de las clases distintas de apariencia en Kant ilumina también las formas que distingue Marx. En concreto, el concepto de apariencia trascendental de Kant puede ponerse en conexión con el concepto de fetichismo de Marx; y el de apariencia lógica, con el de mistificación ${ }^{42}$.

G. Lebrun en su importante estudio Kant y el final de la metafisica, aísla dos estructuras de apariencia en Kant: la apariencia trascendental, bien conocida, ubicada en la "Dialéctica trascendental"; y la apariencia lógica, en la propia "Analítica Trascendental", la "lógica de la verdad"43.

La apariencia trascendental es la ilusión que surge cuando la razón trata de encontrar, pues tal es su destinación [Bestimmung], la totalidad absoluta de toda experiencia posible como unidad ${ }^{44}$ : unidad, la de lo incondicionado, que solo puede ser trascendente, es decir, darse más allá de la experiencia o serie de condiciones. Es una forma de apariencia, por tanto, que surge cuando principios que son subjetivos se toman como constitutivos de objetos. Lo dice Kant:

\begin{abstract}
¿De dónde procede la Apariencia dialéctica en las Ideas trascendentales? De aquello que produce toda apariencia, a saber, la confusión de las condiciones subjetivas de nuestro pensamiento con las condiciones objetivas. No podemos evitarlo, pues debemos pensar un objeto incondicionado y no hay ninguna otra manera de pensarlo más que la que incluye en sí la naturaleza particular de nuestro sujeto ${ }^{45}$.
\end{abstract}

De aquí la inevitabilidad de la apariencia: "La razón de esto se halla en que hay en nuestra razón [...] reglas básicas y máximas para aplicarla que tienen todo el aspecto de principios objetivos. Debido a tales principios, se toma la necesidad subjetiva de cierta conexión -favorable al entendimiento- de nuestros conceptos por una necesidad objetiva de determinación de las cosas en sí mismas" ${ }^{46}$. Tenemos, pues, una apariencia inevitable, pues principios de nuestra razón aparecen como principios objetivos, constitutivos de las cosas.

${ }^{42}$ Ha habido algunos intentos de utilizar la filosofía trascendental kantiana como modelo para una ontología social. Cf. Christian Krijnen, The very idea of organization. Social Ontology today: Kantian and Hegelian reconsiderations, Leiden, Brill, 2015, donde se ofrece una fundamentación a la ontología social desde la filosofía trascendental kantiana

${ }^{43}$ Gérard Lebrun, Kant y el final de la metafisica, Madrid, Escolar y Mayo, 2008, p. 100-101.

${ }^{44}$ Immanuel Kant, Crítica de la razón pura, traducción de P. Ribas, Madrid, Alianza, 2002, B 352, p. 298 (en adelante KrV, se cita paginación de la Academia y de la traducción de Ribas)

${ }^{45}$ Gérard Lebrun, op. cit., p. 71.

${ }^{46} \mathrm{KrV}$, A 297, p. 299.

Araucaria. Revista Iberoamericana de Filosofia, Política, Humanidades y Relaciones Internacionales, año $22, \mathrm{n}^{\circ} 43$. Primer semestre de 2020. Pp. 169-195. ISSN 1575-6823 e-ISSN 2340-2199 https://dx.doi.org/10.12795/araucaria.2020.i43.08 
¿No recuerda esto a una forma de apariencia que emerge cuando formas de relación social aparecen o se manifiestan como propiedades de las cosas? La apariencia del fetichismo consiste en que principios subjetivos, las relaciones sociales, aparecen como principios constitutivos de objetos, como propiedades de las cosas. Esta descripción de Marx en los Grundrisse de lo que más tarde denominará sistemáticamente fetichismo del dinero lo expone con claridad:

Lo que vuelve particularmente difícil la comprensión del dinero en su pleno carácter determinado como dinero [...] consiste en que aquí una relación social, determinado vínculo entre los individuos, aparece como metal, como piedra, como objeto plenamente corpóreo al margen de esos individuos y al que se encuentra como tal en la naturaleza; resulta imposible, distinguir en él aquella determinación formal de su existencia natural ${ }^{47}$.

Hay un claro paralelismo con el fenómeno de la apariencia trascendental: en el fetichismo, lo que nos confunde es que nuestra (inter)subjetividad social se proyecta o aparece como propiedad constitutiva de un objeto. En fin: la apariencia trascendental consiste en que principios que son subjetivos se toman como constitutivos de objetos. Análogamente, la apariencia del fetichismo consiste en que principios subjetivos, las relaciones sociales, aparecen como principios constitutivos de objetos, como propiedades de las cosas.

La apariencia lógica en Kant no es tan conocida. Parece que el "territorio de la verdad", esta isla, esta pequeña reserva de tierra firme, como lo describe Kant, está a salvo, rodeada y azotada por "el océano ancho y borrascoso, verdadera patria de la ilusión" seno una forma de ilusión, no menos pertinaz. Hay una lógica de la apariencia en el funcionamiento del entendimiento, constitutiva al discurso de la verdad, que Kant analiza en el Apéndice de la "Analítica"49. Esta apariencia consiste en que, inadvertidamente, principios que pertenecen a un plano meramente lógico se aplican a lo sensible. Recordemos que Kant quiere replantear el concepto mismo de lógica como lógica trascendental, es decir, aquella forma del pensamiento que contiene, si bien a priori, una referencia al objeto. Sin esta referencia, el pensar es vacío. Una ontología forjada sobre el armazón de la lógica, que no considera las condiciones de la sensibilidad como originarias, simplemente no alcanza a la realidad efectiva y se queda tan sólo en la mera referencia a la cosa en general; es, afirma Lebrun, una "fantasmagoría" ${ }^{50}$. La

${ }^{47}$ Karl Marx, Grundrisse der Kritik der politischen Ökonomie (Rohentwurf) 1857-1858, MEW 42, p. 151.

${ }_{48}$ Krv, B 295-A 236, p. 259.

49 "La anfibología de los conceptos de reflexión a causa de la confusión del uso empírico del entendimiento con el trascendental" y "Observación sobre la anfibología de los conceptos de reflexión".

${ }^{50}$ Gérard Lebrun, op. cit., p. 65. 
ontología clásica ignoraba este peligro. Escribe Lebrun "Para ella, la palabra «vacío» (sinnleer) no quería decir nada. Puesto que el sentido tan sólo era la sombra proyectada de la cosa, dada en la intuición intelectual, ¿por qué nos inquietaríamos por saber si la mera significación de una palabra se refería o no a un objeto, o si podía o no referirse a «algo en general» ${ }^{51}$ Es la definición de dogmatismo de la metafísica clásica racionalista: “[...] la pretensión de avanzar con puros conocimientos conceptuales (los filosóficos) conformes a unos principios - tal como la razón los bien empleando desde hace mucho tiempo-, sin haber examinado el modo ni el derecho con que llega a ellos. El dogmatismo es, pues, el procedimiento dogmático de la razón pura sin previa crítica de su propia capacidad ${ }^{52}$. Esta ilusión consiste, en una palabra, en dejar escapar el objeto: "Pero si con dichos conceptos queremos llegar a los objetos, necesitamos primero una reflexión trascendental que determine de qué facultad cognoscitiva han de ser objetos, si del entendimiento puro o de la sensibilidad" 53 .

Pues bien, ¿no se reflejaría este afán de no perder la referencia a la cosa, a la peculiaridad de la dimensión material, en la crítica de Marx al excesivo formalismo, que encuentra su culminación en la mistificación, esto es, el proceso por el cual, inadvertidamente, principios meramente jurídico-formales se aplican a una relación real-material, haciendo que se manifieste lo contrario de lo que dicha en realidad es? En efecto, en todas las formas de mistificación, en las cuales una forma de aparición encubre la relación efectiva, hay una constante: esa forma de aparición toma la forma de un intercambio entre equivalentes, entre mercancías - la fuerza de trabajo, el propio capital, la tierra-. En el capítulo del salario, dice Marx que en esta forma de aparición que oculta la relación esencial y muestra su contrario reposan todas las representaciones y mistificaciones del modo de producción capitalista, todas sus ilusiones, toda la cháchara apologética ${ }^{54}$. Es la crítica general de Marx al intercambio de equivalentes -y el salario es la forma por antonomasia de este pretendido intercambio- como forma de aparición superficial que iguala y neutraliza las diferencias que de facto se dan en la materialidad realmente efectiva de las relaciones económicas, esenciales. Como la Monadología de Leibniz, el mundo mistificado de la esfera del intercambio de equivalentes es un mundo que vive de omitir las diferencias reales ${ }^{55}$. Escribe Marx en los Grundrisse:

${ }^{51}$ Gérard Lebrun, op. cit., p. 59.

${ }^{52} \mathrm{Krv}, \mathrm{B} X X X V$, p. 30.

${ }^{53} \mathrm{KrV}$, A 270-A 270, p. 282. Cursiva nuestra

${ }^{54}$ MEW 23, p. 562.

${ }^{55}$ Kant escribe a propósito de la Monadología de Leibniz: : “[...] es éste una especie de mundo encantado a cuya admiración debe haberse visto inducido ese hombre célebre por la sola razón de que él veía en las representaciones sensibles, como fenómenos, no un tipo de representación totalmente diferente de todos los conceptos, o sea intuición -como debe ser-, sino un conocimiento, aunque confuso, que tienen su sede en el entendimiento y no en la sensibilidad" (Immanuel Kant, Los 
La circulación, que se presenta como lo inmediatamente existente en la superficie de la sociedad burguesa, existe sólo en la medida en que se la mantiene. Considerada en sí misma, es la intermediación entre extremos que le están presupuestos. No pone a esos extremos. Por ende no sólo debe medírsele en cada uno de sus momentos, sino como totalidad de la intermediación, como proceso total. Su ser inmediato es, pues, apariencia pura [sein unmittelbares Sein ist daher reiner Schein]. Es el fenómeno de un proceso que ocurre por detrás de ella ${ }^{56}$.

En las relaciones monetarias, dice Marx, todas las contradicciones inmanentes de la sociedad burguesa se borran. Mercancías y trabajo pasan a igualarse como valores de cambio, la relación entre ellos se representa como intercambio de equivalentes, y los individuos que lo llevan a cabo se determinan simplemente como intercambiantes, y "No existe absolutamente ninguna diferencia entre ellos, en cuanto a la determinación formal, que es también la determinación económica, la determinación ajustándose a la cual se ubican esos individuos en la relación de intercambio; el indicator [índice] de su función social o de su relación social mutua" ${ }^{57}$. De aquí nacen unas ciertas nociones abstractas de igualdad y libertad: igualdad, porque se ven obligados a cumplir la ley de intercambio de equivalentes, y realizan dicha igualdad efectivamente al igualarse todos socialmente como sujetos de necesidades y trabajos diferentes, que se integran en un todo mediante en el intercambio; libertad, porque los que intercambian no utilizan la violencia, sino que se reconocen mutuamente como propietarios que voluntariamente enajenan su mercancía. Así nace la noción jurídica de persona. No es que en el intercambio se respete esta libertad e igualdad, sino que el intercambio es su base real. De aquí el a menudo malentendido punto de vista de Marx acerca de estas relaciones jurídicas: "Estas, como ideas puras, son meras expresiones idealizadas de aquél al desarrollarse en relaciones jurídicas, políticas y sociales, éstas son solamente aquella base elevada a otra potencia" 58 . Marx no reduce la idea general e igualdad o de libertad a las relaciones económicas, sino que acota: "La igualdad y la libertad en este sentido constituyen precisamente lo contrario de la libertad e igualdad en la Antigüedad, [...]"59. Este tipo de libertad y de igualdad abstractas es la forma fenoménica en la cual aparecen las relaciones económicas capitalistas, cuyo contenido efectivo queda borrado en el marco general y universal del intercambio y el dinero. En efecto, el dinero borra, lo hemos visto en la mistificación del salario, la diferencia entre sujetos

progresos de la Metafisica desde Leibniz y Wolff, traducción de F. Duque, Madrid, Tecnos, 2002, XX 284, p. 52).

${ }^{56} \mathrm{MEW}$ 42, p. 165.

${ }^{57}$ MEW 42, p. 152-153.

${ }_{58} \mathrm{MEW} 42$, p. 156.

${ }_{59} \mathrm{MEW} 42$, p. 156. Cursiva nuestra. 
y entre objetos: "La diferencia natural y específica existente en la mercancía se desvanece; constantemente la borra la circulación. [...] Pero en la medida en que el dinero se presenta aquí como material, como mercancía general de los contratos, se borra más bien toda diferencia entre contratos y partes contratantes" $" 60$. A partir de estas consideraciones, Marx elabora una intensa crítica al escamoteo sistemático de la dimensión de materialidad, de diferencias reales, a favor de categorías abstractas. Su crítica recuerda a la crítica kantiana al dogmatismo:

No poner de relieve en esta concepción [la del dinero] las connotaciones históricas, sino contraponerla, como refutación, a las relaciones económicas más desarrolladas -en las cuales los individuos ya no se vinculan entre sí meramente como sujetos del intercambio o compradores o vendedores, sino que establecen entre sí relaciones determinadas y ya no pueden ser incluidos todos bajo un solo carácter determinado-, es lo mismo que afirmar que no existe diferencia alguna, y menos aún contraposición y contradicción, entre los cuerpos naturales, ya que éstos, por ejemplo en lo relativo a la pesantez, son todos pesados y por tanto iguales; o son iguales porque todos adoptan las tres dimensiones del espacio. De la misma manera, se toma aquí al valor de cambio en su carácter desarrollado simple, y no en sus formas más desarrolladas, que son contradictorias ${ }^{61}$.

Dejarse guiar por la estructura que parece mostrar la forma de aparición del dinero, esto es, asumir que todos los propietarios y mercancías quedan igualados, equivale, para Marx, a obviar que existen relaciones de oposición entre cuerpos tan sólo porque todos son pesados. De igual modo que hay relaciones reales de oposición entre cuerpos, a pesar de que todos sean mensurables como pesados, así también existen relaciones antagónicas entre el capital y el trabajo, en su nivel real y material, por mucho que ambos puedan y de hecho tomen, como su forma de aparición, la forma de dinero o valor de cambio. Quedarse tan sólo con categorías abstractas invisibiliza y hace desaparecer las diferencias reales, efectivas. El concepto de "oposición real" que maneja Marx aquí, nótese, es el kantiano, para señalizar la dimensión irreductible a concepto en un cuerpo ${ }^{62}$. Marx continúa con un pasaje de inspiración hegeliana:

${ }^{60}$ MEW 42, p. 158.

${ }^{61}$ MEW 42, pp. 158-159.

${ }^{62}$ Oposición real se define para Kant como aquella donde “[...] un motivo real elimina el efecto del otro. Sólo en la sensibilidad encontramos las condiciones para representarnos esta última oposición" $\mathrm{KrV}$, B 330-A 274, p. 285. "El hecho del choque prueba enseguida empero que, para ser conocidas, las cosas en el espacio no deben ser meramente representadas por conceptos del entendimiento como cosas en sí sino también, y según su intuición sensible, como fenómenos; [...]”. (Kant, I., Los progresos, op. cit., XX p. 280, p. 47).

Araucaria. Revista Iberoamericana de Filosofia, Politica, Humanidades y Relaciones Internacionales, año $22, \mathrm{n}^{\circ} 43$. Primer semestre de 2020. Pp. 169-195. ISSN 1575-6823 e-ISSN 2340-2199 https://dx.doi.org/10.12795/araucaria.2020.i43.08 
En la evolución de la ciencia esas determinaciones abstractas son las primeras en aparecer y las más pobres, tal como también ocurre, en parte, históricamente; lo más desarrollado es lo posterior. En el conjunto de la sociedad burguesa actual, esta reducción a precios y a su circulación, etc., aparece como el proceso superficial bajo el cual, empero, ocurren en la profundidad procesos completamente diferentes, en los cuales aquella igualdad y libertad aparentes de los individuos se desvanecen ${ }^{63}$.

El marco de Marx es aquí la distinción de Hegel entre lo abstracto y lo concreto, mientras que Kant opera, su crítica al dogmatismo, con la distinción entre entendimiento y sensibilidad; pero en ambos casos, se reclama una dimensión de realidad efectiva, sensible, material, de la que no puede darse cuenta con conceptos meramente abstractos o lógicos. Para Hegel y Marx, lo primero que aparece ante el saber son las ideas abstractas, a las que se escapa de pleno la determinación pletórica de la cosa concreta; para Kant, los metafísicos dogmáticos, dejándose llevar por la potencia del entendimiento, creen poder alcanzar a la cosa en sí por meros conceptos. En ambos casos, lo real se escapa ${ }^{64}$ entre las manos y resta tan sólo un pálido fantasma, una sombra de la realidad.

Un poco más adelante, critica Marx a economistas como Bastiat, que reducen las relaciones complejas de la sociedad burguesa a las relaciones de intercambio de equivalentes. Estos autores reducen la categoría compleja del capital, interés, etc., a la de cambio. ¿Qué supone esto? Perder las diferencias reales:

Se abstraen todas las relaciones en su carácter determinado específico y retornan a la relación, aún no desarrollada, de intercambio de una mercancía por otra. Si abstraigo de un concreto lo que lo distingue de su abstracto, no obtengo otra cosa que lo abstracto. De este modo todas las categorías económicas se convierten en más y más nombres para la misma relación de siempre, y esta burda incapacidad para captar las diferencias reales termina por ser la presentación del common sense [sentido común] puro. Las «armonías económicas» del señor Bastiat significan au fond [en el fondo] que existe una sola relación económica, la cual adopta diversos nombres, o que sólo en cuanto a los nombres se produce una diferencia ${ }^{65}$.

Si abstraigo de un concreto lo que lo distingue de su abstracto, no obtengo otra cosa que lo abstracto, dice Marx. Kant decía, recordemos: si ciertos entes son particulares, lo son precisamente por contener más de lo pensado en el concepto. Cuando se hace abstracción de este plus quedándose uno con el mero

\footnotetext{
${ }^{63}$ MEW 42, p. 159.

${ }^{64}$ Para una exposición del papel de la abstracción en la crítica de la economía política de Marx, cf. César Ruiz Sanjuán, Historia y sistema en Marx. Hacia una teoría crítica del capitalismo, Tres Cantos, Siglo XXI, 2019, p. 189 y ss.

${ }^{65}$ MEW 42, p. 188.
} 
concepto de una cosa, continuaba, se reduce la cosa a su concepto y lo particular se declara inexistente ${ }^{66}$. Tenemos, rigurosamente, en ambos autores, el mismo pensamiento. A juicio de Marx, en estos intentos de los economistas lo que se pierde, a lo que no se llega, es a las "diferencias reales", a "lo concreto", al "carácter determinado específico". Se hace una falsa generalización, se hurta una dimensión particular: se universaliza falsamente a todos los sujetos como propietarios de mercancías. Se pierde una especificidad, un lugar que es el de una sensibilidad no formal.

Pero Marx no profesa un empirismo ingenuo, todo lo contrario: es, con Hegel, consciente de la necesidad de la paciencia del concepto para llegar a lo real, de la múltiple mediación de lo concreto. Marx distingue justo a continuación entre la reducción científica, que reduce datos a una relación económica real para dejar de lado las diferencias irrelevantes producidas por el desarrollo, y la simplificación de los economistas, que escamotean ora este aspecto, ora este otro, para que la identidad aparezca bien por aquí, bien por allá. De lo que reniega Marx no es del concepto, sino de la abstracción vacía, que por pretender ser la más apegada a la realidad se queda en la superficie y en la vana generalidad y no alcanza las diferenciaciones reales. Para los economistas, las diferencias reales son meros nombres; para él, allí donde se juega todo.

Puede leerse este pasaje en estricto paralelo con la "Estética trascendental", donde Kant, a propósito del tiempo como condición a priori de nuestra sensibilidad, Kant dice lo siguiente: el tiempo no es nada si hacemos abstracción de nuestro modo de intuir - tanto interna como externamente- y tomamos a los objetos como son en sí mismos. Sin embargo, es necesariamente objetivo en relación con los fenómenos, es decir, con todo lo que puede presentársenos en la experiencia. De aquí, a la vez, la realidad empírica del tiempo y su idealidad trascendental. Kant señala aquí lo que ocurre cuando hablamos de cosas en sí mismas: que hacemos abstracción de ciertas condiciones particulares que impone nuestra sensibilidad. El tiempo no es nada, pero porque ponemos entre paréntesis, no consideramos, nuestra facultad de intuir. Pero esto no es sino otra manera de decir: si solo pensamos por conceptos, abstrayéndonos de nuestra manera de intuir, sólo hacemos lógica. No hablamos de las cosas. Hacemos abstracción, sí, de una condición particular nuestra, pero de aquella bajo la que, específicamente, se nos dan a nosotros las cosas, y no pueden dársenos de otra manera. Ignorarla supone, pues, volver la espalda al objeto y pensar sólo nuestros propios conceptos.

Naturalmente, como decía Marx, si abstraigo de un concreto lo que le diferencia de un abstracto, me queda sólo lo abstracto; es lo que ocurre, justamente, cuando abstraigo de un fenómeno lo que le diferencia de la cosa en

${ }^{66} \mathrm{KrV}$, B 337-A 281, p. 289. Cursiva nuestra.

Araucaria. Revista Iberoamericana de Filosofia, Política, Humanidades y Relaciones Internacionales, año 22, $\mathrm{n}^{\circ} 43$. Primer semestre de 2020. Pp. 169-195. ISSN 1575-6823 e-ISSN 2340-2199 https://dx.doi.org/10.12795/araucaria.2020.i43.08 
sí, a saber, su estar-dado para la sensibilidad. Entonces, claro, sólo me quedo con lo abstracto, el concepto de cosa en general, y prescindo de lo propio, el tiempo; pero así pierdo lo concreto mismo, el fenómeno. Escribe Kant:

\footnotetext{
"No podemos decir que todas las cosas estén en el tiempo, ya que el concepto de cosas en general prescinde de cómo sean intuidas. Ahora bien, la forma de ser intuidas es precisamente la condición bajo la cual entra el tiempo en la representación de los objetos. Si se incluye en el concepto tal condición y se afirma que todas las cosas, en cuanto fenómenos [...] están en el tiempo, el principio es correcto y tiene su universalidad a priori" ${ }^{67}$.
}

No podemos decir "todas las cosas están en el tiempo", pero sí: "todas las cosas -como fenómenos- están en el tiempo". Es necesario acotar la generalidad "cosa", es necesario tener en cuenta las condiciones del darse. Así ganamos la validez para el "todo". De igual modo, Marx podría decir: "Todas las cosas - como mercancía - tienen valor de cambio". Se trata de mantener ante la vista las condiciones concretas (fuerza de trabajo, mercancía) para determinar la categoría más general (cosa).

Este es, en fin, todo el problema de la mistificación: hay mistificación cuando se olvidan las condiciones del darse las cosas bajo condiciones capitalistas. Se toma la forma de manifestación general "trabajo", se olvida el "fuerza de"; se toma la forma de manifestación general "renta", se olvidan las clases de plusvalor. El tipo de pregunta de Marx y de Kant es el mismo: ¿cómo es que los economistas han omitido la diferencia real entre trabajo y fuerza de trabajo? ¿A qué nivel estaba fuerza de trabajo para no ser visto? ¿Cómo es que los metafísicos han omitido la diferencia real de número, de oposición, etc.? ¿A qué nivel estaba para no ser visto? Estaban, para Marx, en el nivel de la realidad efectiva concreta, para Kant, en el de la sensibilidad. Hay toda una constelación de conceptos, de realidades, que están a un nivel que se nos escapa si sólo utilizamos categorías abstractas y jurídico-formales; o, para Kant, meras categorías del entendimiento.

\section{Conclusiones y vías abiertas}

Dos serían las consecuencias principales que cabe apuntar como balance de lo recorrido hasta aquí. En primer lugar, como conclusión general, parece adecuado considerar a Marx no solo como un científico social, sino, ante todo, como un filósofo, que utiliza el vocabulario de la tradición filosófica clásica, concretamente de Kant y Hegel; el lugar teórico de su obra donde esto aparcería de modo claro es en su proyecto de crítica de la economía política, entendida

${ }^{67} \mathrm{KrV}, \mathrm{B} 52-\mathrm{A} 35$, p. 78. 
ésta como deconstrucción de las formas de apariencia invertidas y cosificadas que estructuran la realidad efectiva de la sociedad moderna.

En segundo lugar, se ha tratado de demostrar que, efectivamente, puede pensarse una afinidad entre las formas de apariencia descritas por Kant como ilusión trascendental y apariencia lógica y las formas de apariencia descritas por Marx como fetichismo y mistificación. El fetichismo, como la apariencia trascendental, consiste en convertir en una cosa lo que no es cosa, sino (inter) subjetividad; la mistificación, como la apariencia lógica, consiste en obviar una cosa que está, que existe como realidad efectiva.

Este análisis sobre los fundamentos teóricos y filosóficos de la teoría de la apariencia de Marx permite superar algunas de las cegueras o callejones sin salida de las corrientes más ortodoxas de la tradición marxista, así como abrir la vía a fructíferas consecuencias políticas de este enfoque ${ }^{68}$. En efecto, la teoría de Marx no es una ontología que flota en el vacío, sino una investigación crítica del proceso total de constitución de lo social [Vergesellschaftung] en la época moderna: una teoría acerca de cómo se construye la totalidad social en las condiciones históricas del modo de producción capitalista. La pregunta de Marx podría formularse, pues, así: ¿cómo ocurre la "síntesis social", cómo se construye el todo-sociedad en la era moderna o el modo de producción capitalista, cuya culminación vivimos hoy? Su respuesta, desde los conceptos de mistificación y fetichismo, nos permite comprender, en primer lugar, las dimensiones de apariencia e inversión que atraviesan esa constitución de lo social, como mostró Sohn-Rethel con su concepto de "abstracción real". En segundo lugar: la pregunta de Marx, y esto es ya una pregunta política, es la pregunta por las condiciones de posibilidad de la síntesis social. A lo largo de sus escritos, Marx muestra que la constitución misma del capital, la lógica de la forma-mercancía generalizada y las relaciones cosificadas y mercantilizadas que genera es, en realidad, lo contrario de una sociedad. A partir de aquí se abre toda una nueva vía de estudio, más dirigida a extraer las consecuencia políticas del planteamiento de Marx. Autores como Polanyi han narrado la historia de los últimos tres siglos como la pugna entre un mercado autorregulado y una sociedad que lucha por protegerse de él ${ }^{69}$. Esa dinámica atraviesa distintas fases, según la lógica interna del capital se despliega progresivamente a través del tiempo y del espacio. Este prisma permite generar un esquema de inteligibilidad para los acontecimientos políticos y sociales de la historia reciente, desde las protestas de los commoners ingleses hasta las revueltas campesinas de Latinoamérica,

\footnotetext{
${ }^{68}$ Algunas de estas consecuencias políticas han sido exploradas en un capítulo en un libro colectivo de próxima aparición, "Las cosas y los vínculos. Marx y el fetichismo de la mercancía en el siglo XXI", en Ramas San Miguel, Clara, Vargas, R. y Pulgar, P. (eds), El eterno retorno de la crítica de la economía política: valor, abstracción real y método, Santiago de Chile, LOM, en prensa.

${ }^{69}$ Polanyi, Karl., La gran transformación. Los orígenes políticos y económicos de nuestro tiempo, México, FCE, 2003; Polanyi, K., "La economía como proceso instituido", en: Textos escogidos, CLACSO, Buenos Aires, 2012.
} 
pasando, por supuesto, por los levantamientos de trabajadores y obreros en el continente europeo. Los textos de Marx esbozan pinceladas que pueden servir como hitos para trazas esta historia.

En una primera fase, esta dinámica se desarrolló en el escenario de Europa, con el nacimiento del capitalismo, que como muestra Marx en su teoría de "la acumulación originaria", históricamente sólo pudo ser impuesto "a sangre y fuego". Así, súbitamente, hacia finales del siglo XV en Inglaterra, masas de personas se vieron arrancadas de sus vínculos colectivos, con la tierra y sus medios de trabajo. Comenzó el proceso de "dislocaciones sociales" lo ha llamado Harvey, "acumulación por desposesión", mediante enclosures de terrenos comunales ${ }^{71}$, cierre de conventos y asistencia a pobres, prohibición de derechos de uso comunes.$^{72}$

El proceso continuó extendiéndose con el colonialismo, que Marx muy agudamente comprendió como la ratio cognoscendi de la verdad de las relaciones económicas capitalistas:

Aquí no nos ocupamos del estado de las colonias. Lo que nos interesa a nosotros es el secreto del viejo mundo que la economía política descubrió en el nuevo y proclamó a viva voz: el modo de producción y de acumulación capitalista, es decir, también la propiedad capitalista, necesariamente producen la aniquilación de la propiedad privada basada sobre el trabajo propio, esto es, la expropiación del trabajador ${ }^{73}$.

Marx proporciona así valiosos precedentes para el estudio de la construcción espacial del capitalismo al entender que "su aporte no radica en la compresión del carácter mundializado del comercio que comienza con la invasión europea a América, sino en la naturaleza planetariamente expansiva de la propia producción capitalista"74.

Las últimas décadas del siglo XX, en fin, bajo la globalización neoliberal, han sido testigo de la expansión total de la lógica de la forma-mercancía y sus efectos sobre el vínculo social. Latinoamérica ha sido uno de los escenarios

\footnotetext{
${ }^{70}$ Polanyi, La gran transformación, op. cit., p. 88.

71 Thomson, E. P., "Mode de domination et révolution en Anglaterre", Actes de la Recherche en sciences sociales, 2-3, 1971. Thomson ha estudiado también las formas de resistencia que se encuentran en las costumbres y formas culturales de las capas plebeyas, en estupenda reedición de Capitán Swing: Thomson, E. P., Costumbres en común. Estudios sobre la cultura popular, Madrid, Capitán Swing, 2019.

${ }^{72}$ Marx estudia nacimiento de las nuevas relaciones capitalistas y cómo ellas disuelven los vínculos sociales previos en su estudio de las leyes alemanas contra el robo de madera que se discutían en la Dieta Renana: Marx, Karl. Los debates de la Dieta Renana. Barcelona: Gedisa, 2007.

73 MEW 23, p. 802.

74 García Linera, A. "La globalización ha muerto". Vicepresidencia Primera del Estado Plurinacional de Bolivia, . Disponible en web: https:/www.vicepresidencia.gob.bo/IMG/pdf/globalization_is_dead. pdf, p. 2, citado en Sánchez Iglesias, Eduardo, "Marx y la cuestión colonial. La dimensión geográfica del colonialismo", en La Migraña 27, 2018.
} 
donde con mayor fuerza se implementó el programa neoliberal, especialmente en los momentos de crisis económica: desde el experimento chileno del golpe de Estado de 1973, pasando por brutales procesos de privatización, desregulación financiera y precarización laboral en toda la región en los 80 y 90, hasta el neoliberalismo impulsado tras la crisis mundial en 2008 (Colombia, Brasil, Chile, Perú, México y Paraguay) ${ }^{75}$.

En fin, un desarrollo posible de la crítica de la economía política de Marx es la lectura de la historia social y política reciente una sociedad que se protege de la lógica del sujeto-capital; es más, es por el potencial configurador de estas mismas relaciones capitalistas que en los últimos siglos la realidad misma adquiere el carácter de objeto social: "La realidad naciente llegó a nuestra conciencia bajo la forma de la economía política"76, afirma Polanyi. Cabría hacer entonces una reconstrucción de la historia política y social de la Modernidad desde estas categorías de la crítica marxiana y su iluminación de la construcción específica de vínculos sociales cosificados y mercantilizados. Ello será, con toda seguridad, el objeto de próximos artículos.

\section{Referencias bibliográficas:}

Backhaus, H.-G., "Zur Marxschen «Revolutionierung» und «Kritik» der Ökonomie: die Bestimmung ihres Gegenständes als Ganzes «verrückter Formen»", en: Dialektik der Wertform. Untersuchungen zur Marxschen Ökonomiekritik, Ça Ira, Freiburg, 2011, pp. 299-333

Breda, S., Boveiri, K., Wolf, F. O. (eds.), Materialistische Dialektik bei Marx und über Marx hinaus, Berlin, Freie Universität Berlin 2017.

Deleuze, G., Kant y el tiempo, Buenos Aires, Cactus, 2008.

Fischer, A. M, Der reale Schein und die Theorie des Kapitals bei Marx, Zürich, Europa Verlag, 1978.

García Linera, A. "La globalización ha muerto". Vicepresidencia Primera del Estado Plurinacional de Bolivia, . Disponible en web: https://www. vicepresidencia.gob.bo/IMG/pdf/globalization_is_dead.pdf.

Hegel, G. W. F., Ciencia de la lógica. Vol. I: Lógica objetiva (1812-1813), edición de F. Duque, Madrid, Abada, 2011.

Heinrich, M., Die Wissenschaft vom Wert. Zwischen klassicher Tradition und wissenschtflicher Revolution, Münster, Westfälisches Dampfboot, 2011.

Kant, I., Gesammelte Schriften. Hrsg. von der Königlich-Preussischen Akademie der Wissenschaften zu Berlin, 1902 y ss.

${ }^{75}$ López Segrera, F., América Latina: crisis del posneoliberalismo y ascenso de la nueva derecha, CLACSO, Buenos Aires, 2016

${ }^{76}$ Polanyi, La gran transformación, op. cit., p. 135.

Araucaria. Revista Iberoamericana de Filosofia, Politica, Humanidades y Relaciones Internacionales, año $22, \mathrm{n}^{\circ} 43$. Primer semestre de 2020. Pp. 169-195. ISSN 1575-6823 e-ISSN 2340-2199 https://dx.doi.org/10.12795/araucaria.2020.i43.08 
Kant, I., Crítica de la razón pura, traducción de P. Ribas, Madrid, Alianza, 2002.

Kant, I., Los progresos de la Metafísica desde Leibniz y Wolff, traducción de F. Duque, Madrid, Tecnos, 2002.

Krijnen, Ch., The very idea of organization. Social Ontology today: Kantian and Hegelian reconsiderations, Leiden, Brill, 2015.

Lebrun, G., Kant y en final de la metafísica. Ensayo sobre la Crítica del Juicio, Madrid, Escolar y Mayo, 2008.

López Segrera, F., América Latina: crisis del posneoliberalismo y ascenso de la nueva derecha, CLACSO, Buenos Aires, 2016.

Marx, K., Grundrisse der Kritik der politischen Ökonomie (Rohentwurf) 18571858, Marx-Engels Werke, Berlin, hrsg. Vom Institut für MarxismusLeninismus beim Zk der SED, 1956 ff., Bd. 42

Marx, K., Das Kapital. Kritik der politischen Ökonomie. Erster Band: Der Produktionsprozess des Kapitals, Marx-Engels Werke, Berlin, hrsg. Vom Institut für Marxismus-Leninismus beim Zk der SED, 1956 ff., Bd. 23.

Marx, K., Das Kapital. Kritik der politischen Ökonomie. Dritter Band: Der Gesamtprozess der kapitalistischen Produktion, Marx-Engels Werke, Berlin, hrsg. Vom Institut für Marxismus-Leninismus beim Zk der SED, 1956 ff., Bd. 25.

Marx, K. Los debates de la Dieta Renana. Barcelona, Gedisa, 2007.

Marx, K., Theorien der Mehrwert, Marx-Engels Werke, Berlin, hrsg. Vom Institut für Marxismus-Leninismus beim Zk der SED, 1956 ff., Bd. 26.1-3.

Navarro Cordón, J. M., "El concepto de 'trascendental' en Kant", Anales del Seminario de Metafísica, vol. 5, no 5 (1970), pp. 55-78.

Polanyi, K., "La economía como proceso instituido", en: Textos escogidos, CLACSO, Buenos Aires, 2012.

Polanyi, K, La gran transformación. Los orígenes políticos y económicos de nuestro tiempo, México, FCE, 2003.

Ramas San Miguel, C., "Las cosas y los vínculos. Marx y el fetichismo de la mercancía en el siglo XXI", en Vargas, R. y Pulgar, P. (eds), El eterno retorno de la crítica de la economía política: valor, abstracción real y método, Santiago de Chile, LOM, en prensa.

Ramas San Miguel, C., Fetiche y mistificación capitalistas. La crítica de la economía política de Marx (con un prólogo de C. Fernández Liria y un epílogo de Michael Heinrich), Tres Cantos, Siglo XXI, 2018.

Ramas San Miguel, C., Hacia una teoría de la apariencia. Fetichismo y mistificación en la crítica de la economía política de Marx [tesis doctoral], Madrid, UCM, 2015 < https://eprints.ucm.es/34214/1/T36659.pdf>

Ruiz Sanjuán, C., Historia y sistema en Marx. Hacia una teoría crítica del capitalismo, Tres Cantos, Siglo XXI, 2019. 
Sánchez Iglesias, Eduardo, "Marx y la cuestión colonial. La dimensión geográfica del colonialismo”, en La Migraña 27, 2018.

Schumpeter, J. A., "Karl Marx (1818-1883). La doctrina marxista” [en Diez grandes economistas: de Marx a Keynes, Madrid, Alianza Editorial, 1997], pp. 33 y ss.

Thomson, E. P., Costumbres en común. Estudios sobre la cultura popular, Madrid, Capitán Swing, 2019.

Thomson, E. P., "Mode de domination et révolution en Anglaterre", Actes de la Recherche en sciences sociales, 2-3, 1971.

Wallat, H., "Der Begriff der Verkehrung im Denken von Marx" en Marx-Engels Jahrbuch 2004 (2005), pp. 68-102.

Wolf, D., "Warum konnte Hegels Logik Marx große Dienste leisten?" [en C.E. Vollgraf, R. Sperl, R. Hecker, R., (eds.), Beiträge zur Marx-EngelsForschung, Neue Folge 2010, Hamburg, Argument, 2010].

Žižek, S., El sublime objeto de la ideología, México, Siglo XXI, 1992 
